\title{
Laparoscopic Management of Cholecystogastric Fistula
}

Bilioenteric fistulas are found in $0.2-4.0 \%$ of biliary surgical procedures, and involve the duodenum $(80 \%)$, the colon, and rarely the stomach (less than $5 \%)(1-3)$. Cholecysto-enteric fistulas are rare complications of cholelithiasis, and even rarer complications of gallbladder tumors, and they are generally considered to be a contraindication to laparoscopy (4).

A 62-year-old woman presented with a six-months history of epigastric pain. Serum bilirubin was normal, and alkaline phosphatase and $\gamma$-glutamyltransferase were twice the normal levels. An ultrasound examination showed chronic lithiasic cholecystitis and aerobilia. An upper gastrointestinal examination revealed a biliary-gastric fistula in the common bile duct (Figure 1) which, at endoscopy, was found to be located at the antrum. Endoscopic retrograde cholangiography demonstrated a cholecystogastric fistula and common bile duct stones, which were extracted after endoscopic sphincterotomy.

Pneumoperitoneum was established by the open technique, and a $0^{\circ}$ camera was used. The fundus of the gallbladder was pushed toward the diaphragm, and the stomach was gently retracted downward. Using gentle blunt dissection with the suction-irrigation cannula, the fistula was carefully isolated. The $10-\mathrm{mm}$ epigastric trocar was replaced with a 12- $\mathrm{mm}$ trocar for an EndoGIA 60 stapler. After the stapler had been fired (Figure 2), the gastric suture line was checked by air insufflation through the nasogastric tube. Cholecystectomy was completed, and one abdominal drain was left in place. The operating time was $120 \mathrm{~min}$. The nasogastric tube was removed on the third postoperative day, and the patient was discharged on the seventh postoperative day. One year later, the patient continues to be symptom-free, with a normal upper gastrointestinal series.

Laparoscopic treatment of a bilioenteric fistula requires meticulous technique and good laparoscopic experience (4). Careful exposure of the site of the fistula is essential in order to apply the stapler correctly. It has been suggested that some enteral tissue should be included when in the stapling procedure, due to the danger of later suture leakage if gallbladder tissue is left on the enteral wall (5). In the present case, the fistula was located on the upper wall of the antrum, and closure of the fistula had to be done without causing gastric outlet obstruction.

This report confirms that, with increasing experience and with improved imaging and instrumentation, laparoscopic repair of bilioenteric fistulas is feasible and safe. However, an early conversion to laparotomy should be carried out if any difficulties arise at any stage of the procedure.

G. Nuzzo, F. Giuliante, G. D. Tebala, M. Vellone Dept. of Geriatric Surgery, School of Medicine, Catholic University of Rome, Rome, Italy

\section{References}

1. Palomar de Luis M, Tubia Lanaberea JI, Elorza Orue JL. Fistulas biliodigestivas espontaneas. Rev Esp Enferm Dig 1990; 77: 33-8.

2. Sharma A, Sullivan M, English H, Foley R. Laparoscopic repair of cholecystoduodenal fistulae. Surg Laparosc Endosc $1994 ; 6: 433-5$.

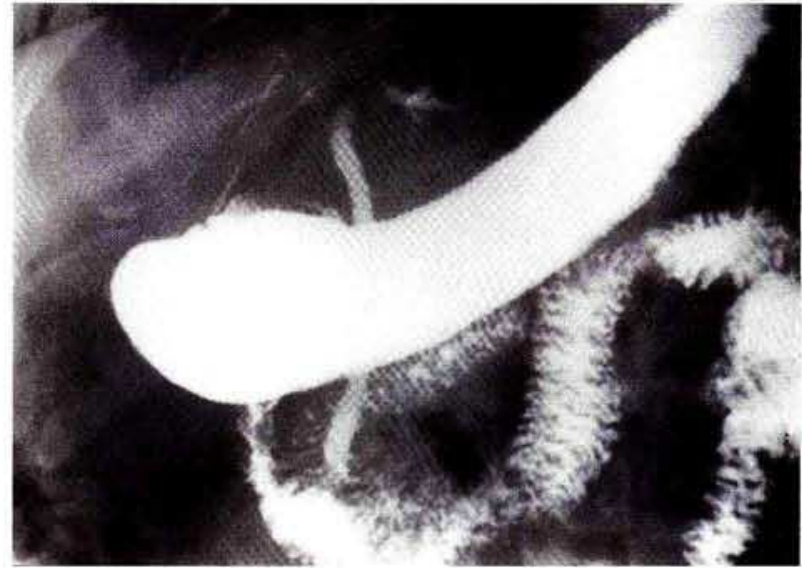

Figure 1: Upper gastrointestinal radiogram, showing a slightly dilated common bile duct without exact definition of the site of the fistula.

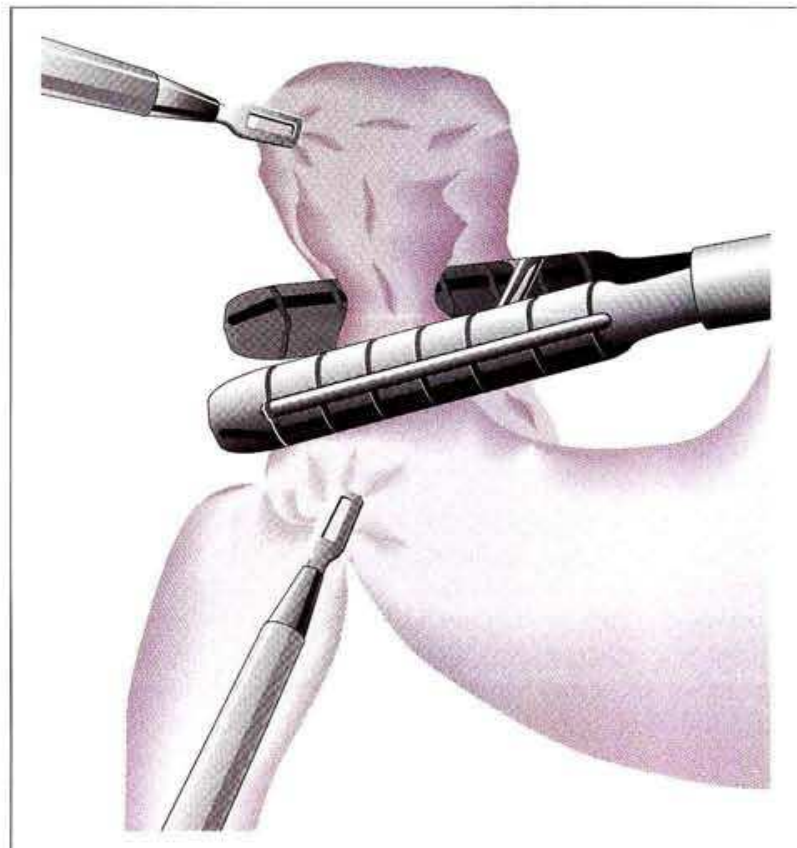

Figure 2: The Endo-GIA 60 stapler was inserted around the cholecystogas tric fistula, with the gallbladder pushed upward and the stomach retracter downward. The stapler is applied with the thin branch being inserted behinc the fistula.

3. Caroli-Bosc FX, Ferrero JM, Grimaldi C, Dumas R, Arpurt JP, Delmont J. Cholecystocolic fistula: from symptoms to diagnosis. Gastroenterol Clin Biol 1990; 14: 767-70.

4. MacIntyre IMC, Wilson RG. Laparoscopic cholecystectomy. Br J Surg 1993; 80: 552-9.

5. Prasad A, Foley RJE. Laparoscopic management of cholecystocolic fistula. Br J Surg 1994; 81: 1789-90.

Corresponding Author

F. Giuliante, M.D., Department of Geriatric Surgery

School of Medicine, Catholic University of Rome

L. Gemelli, 8, 00168 Rome, Italy, Fax: +39-6-3058586 